\title{
IDENTIFIKASI PEWARNA SINTESIS PADA PRODUK OLAHAN BUNGA ROSELLA (Hibiscus sabdariffa) DENGAN METODE KROMATOGRAFI LAPIS TIPIS
}

\author{
Identification of Synthetic Dyes on Rosella Flower Products (Hibiscus sabdariffa) by Thin \\ Layer Chromatography
}

\author{
${ }^{*}$ Rezqi Handayani \& Henilisa Yuliyana Larasati \\ Pharmacy Study Program, Universitas Muhammadiyah Palangkaraya, RTA Milono St. Km.1,5 \\ Palangka Raya, Indonesia \\ *e-mail : rezqi.handayani@gmail.com
}

\begin{abstract}
ABSTRAK
Bahan tambahan pangan sering digunakan atau ditambahkan secara sengaja ke dalam produk olahan makanan atau minuman adalah pewarna. Pewarna terbagi atas dua jenis yaitu pewarna alami dan pewarna sintetis. Sirup yang beredar di masyarakat umumnya banyak mengandung pewarna sintetis, hal ini dilakukan produsen untuk menekan biaya produksi dan membuat tampilan bahan menjadi menarik. Pemakaian pewarna sintetis selain memiliki dampak positif bagi produsen serta konsumen, dapat pula menimbulkan dampak negatif terutama bagi konsumen. Apabila dibandingkan dengan pewarna alami, pewarna sintetis lebih memiliki dampak negatif bagi kesehatan. Saat ini kelompok tani asal Kelurahan Kalampangan mengolah bunga Rosella sebagai sirup. Terbukti dari hasil observasi di lapangan sirup Rosella produksi kelompok tani tersebut cukup dimiminati oleh masyarakat setempat. Oleh karena itu penelitian ini bertujuan untuk menganalisa pewarna sintetik pada produk olahan bunga Rosella yang diproduksi oleh kelompok tani asal Kelurahan Kalampangan, Palangka Raya. Sampel sirup bunga Rosella dianalisa secara kualitatif dengan metode Kromatografi Lapis Tipis (KLT). Pada metode Kromatografi Lapis Tipis perlakuan sampel dilakukan dengan penarikan zat pewarna menggunakan benang wol bebas lemak. Ada 4 (empat) pewarna sintetis yang dialkukan identifikasi pada sampel yaitu Ponceau, Carmoisin, Briliant Blue dan Rhodamin B. Hasil yang di dapatkan adalah pada Eluen I (Etil Metil Keton : Aseton : Air) Rf baku Ponceau 4R 0,7667, Rf baku Carmoisin 0,8266, baku Rf Brilliant Blue 0,7466, dan Rf baku Rhodamin B 0,8667 sedangkan pada sampel tidak terdapat noda. Eluen II ( $2 \mathrm{~g} \mathrm{NaCl}$ dalam Etanol 50\%) didapatkan Rf baku Ponceau 4R 0,9400, Rf baku Carmoisin 0,9400, baku Rf Brilliant Blue 0,6467, dan Rf baku Rhodamin B 0,8867 sedangkan pada sampel tidak terdapat noda. Dari hasi tersebut dapat diketahui bahwa sirup Rosella produksi kelompok tani asal Kelurahan Kalampangan, Palangka Raya tidak mengandung pewarna sintetis.
\end{abstract}

Kata kunci: Pewarna sintesis, Sirup Bunga Rosella, Kromatografi Lapis Tipis

\begin{abstract}
Food additives are often used or added intentionally into processed food or beverage products are dyes. Dyes are divided into two types: natural dyes and synthetic dyes. Syrup circulating in the community generally contains a lot of synthetic dyes, this is done by manufacturers to reduce production costs and make the appearance of materials to be attractive. The use of synthetic dyes in addition to having a positive impact for producers and consumers, can also cause negative impact, especially for consumers. When compared with natural dyes, synthetic dyes have more negative impact on health. Currently farmer groups from Kalampangan Village treat Rosella as syrup. Evident from the observations in the field Rosella syrup production of farmers groups are quite dimiminati by community setelmpat. Therefore this study aims to analyze synthetic dyes on Rosella processed products produced by farmer groups from Kalampangan Urban Village, Palangka Raya. Rosella flower syrup samples were analyzed qualitatively by Thin Layer Chromatography (TLC) method. In the Thin Layer Chromatography method the sampling treatment was carried out by the withdrawal of the dye using a fat free wool yarn. There are 4 (four) synthetic dyes identified by the identification in the sample Ponceau, Carmoisin, Briliant Blue and Rhodamin B. The result obtained is on Eluen I (Ethyl Methyl Keton: Acetone: Water) Rf raw Ponceau 4R 0.7667, Rf raw Carmoisin 0.8266, Rf Brilliant Blue 0.7466 raw, and Rf raw Rhodamin $B 0.8667$ while in the sample there is no stain. Eluen II (2 g NaCl in 50\% Ethanol) obtained Rf Ponceau 4R standard 0.9400, Rf raw Carmoisin 0,9400, Rf Brilliant Blue 0.6467 standard, and Rf standard Rhodamin B 0.8867 while in the sample there were no stains. From the results can be seen that Rosella syrup production from Kalampangan, Palangkaraya does not contain synthetic dyes.
\end{abstract}

Keywords: Synthetic dyes, Rosella flower syrup, Thin Layer Chromatography 


\section{PENDAHULUAN}

Makanan serta minuman merupakan salah satu kebutuhan dasar manusia yang terpenting dan juga merupakan faktor yang sangat esensial bagi pertumbuhan dan perkembangan manusia. Penambahan bahan tambahan pangan ke dalam produk makanan atau minuman bertujuan agar menarik perhatian konsumen. Makanan dan minuman yang tersedia di pasar maupun swalayan tanpa adanya bahan tambahan pangan menjadi kurang menarik, tidak dapat dinikmati dan tidak awet. Salah satu masalah pangan yang memerlukan pemecahan yaitu penggunaan bahan tambahan pangan untuk keperluan pada industri pengolahan pangan, maupun dalam pembuatan makanan dan minuman, yang umumnya dihasilkan oleh industri kecil atau rumah tangga (Winarno dan Rahayu, 1994).

Menurut Purba (2009), Bahan Tambahan Pangan adalah senyawa (atau campuran berbagai senyawa) yang sengaja ditambahkan ke dalam makanan dan minuman dalam proses pengolahan, pengemasan dan penyimpanan dan bukan merupakan bahan (Ingredient) utama. Bahan Tambahan Pangan tersebut dapat berupa pengawet, pewarna, pemanis, penyedap, antioksidan, antikempal, dan pengemulsi. Menurut Peraturan Menteri Kesehatan Republik Indonesia No. 033 Tahun 2012 menyebutkan pewarna sebagai salah satu bahan tambahan pangan dapat berupa pewarna alami (Natural Colour) dan pewarna sintetis (Syntetic Colour), yang ketika ditambahkan atau diaplikasikan pada pangan mampu memberi atau memperbaiki warna.

Salah satu jenis bahan tambahan pangan yaitu pewarna secara umum sering digunakan dalam makanan ataupun minuman olahan terbagi atas pewarna sintetis (buatan) dan pewarna natural (alami). Pewarna sintetis pada umumnya terbuat dari bahan-bahan kimia. Misalnya Ponceau 4R, Carmoisin, Briliant Blue, Tartrazin, atau Allura Red merupakan pewarna sintetis yang masih diperbolehkan penggunaannya. Kadang-kadang pengusaha nakal juga menggunakan pewarna bukan makanan (non-food grade) untuk memberikan warna pada makanan. Salah satu contoh pewarna bukan makanan adalah Rhodamin $B$ yang sebenarnya diperuntukan untuk pewarnaan tekstil (Nugraheni, 2013).

Pemakaian pewarna sintetis selain memiliki dampak positif bagi produsen serta konsumen, dapat pula menimbulkan dampak negatif terutama bagi konsumen. Apabila dibandingkan dengan pewarna alami, pewarna sintetis lebih memiliki dampak negatif bagi kesehatan. Hal ini dikarenakan zat-zat sintetis jika pemakaian yang terus menerus dan dalam jangka waktu yang lama, akan mempengaruhi organ di dalam tubuh. Penggunaan bahan pewarna buatan yang dilarang dapat menyebabkan gangguan kesehatan. Pewarna yang dilarang dapat meracuni ginjal dan mengakibatkan gangguan fungsi hati maupun kanker karena umumnya pewarna yang dipakai merupakan pewarna tekstil (Irianto \& Waluyo, 2007).

Salah satu produk minuman yang sering ditambahkan dengan zat warna adalah sirup. Minuman ini sangat digemari karena warna yang menarik serta cara penyajiannya yang mudah dan sederhana. Sirup yang beredar dimasyarakat umumnya tidak berasal dari pewarna alami yang didapatkan dari tumbuhan, hewan atau mineral, kebanyakan warna yang terkandung didalam sirup merupakan pewarna sintetis untuk makanan. 
Sehingga dalam sirup Rosella diduga juga mengandung pewarna sintetis.

Rosella sendiri sudah banyak dikembangkan di pulau Jawa dan banyak penelitian mengenai tanaman ini. Di Kalimantan sendiri khususnya di kota Palangka Raya, Kalimantan Tengah sudah ada produsen yang memproduksinya, salah satunya di Kelurahan Kalampangan yang mengolahnya dalam bentuk kemasan seperti teh dan sirup dari bunga Rosella. Rosella sangat potensial untuk dikembangkan sebagai bahan baku makanan dan minuman karena nilai nutrisi yang terkandung dalamnya, seperti vitamin $A, C$, $D, B_{1}$ dan $B_{2}$. Pada umumnya setelah pemanenan Rosella diproses menjadi beberapa olahan seperti sirup. Proses pembuatan yang panjang serta suhu yang ekstrim dapat membuat warna alami dari Rosella akan rusak sehingga produk olahan tersebut perlu ditambahkan pewarna sintetis. Zat pewarna sintetis juga lebih murah dan dapat mengefisiensikan pengolahan produk, sehingga dapat menekan biaya produksi.

Metode kromatografi yang dilakukan adalah pemeriksaan larutan uji dan larutan pembanding yang ditotolkan pada lempeng dengan menggunakan teknik Kromatografi Lapis Tipis (KLT). Menurut Farmakope Indonesia Edisi III (1979) Kromatografi Lapis Tipis (KLT) umumnya lebih berguna untuk uji identifikasi karena cara ini khas dan mudah dilakukan untuk zat dengan jumlah sedikit. Kromatografi merupakan metode yang umum dilakukan sebagai pemeriksaan awal suatu senyawa atau zat serta memberikan resolusi yang kurang baik dan kadang-kadang bercak atau noda tidak terbentuk dengan baik. Metode kromatografi tidak sebaik metode spektrofotometri yang memiliki tingkat keakuratan yang tinggi.
Berdasarkan permasalahan di atas peneliti tertarik untuk melakukan analisa pewarna sintetis pada produk olahan bunga Rosella yang beredar di kota Palangka Raya dengan menggunakan metode kromatografi.

\section{METODOLOGI}

\section{Tempat Penelitian}

Penelitian dilaksanakan dilaksanakan di Laboratorium Kimia dan Laboratorium Instrumen Fakultas IImu Kesehatan Universitas Muhammadiyah Palangkaraya.

\section{Alat dan Bahan}

Alat yang digunakan selama penelitian ini diantaranya adalah Spektrofotometer UV-Vis Shidmazu type UV-1700, Kuvet, Neraca analitik, Gelas Ukur 100 mL, Beaker Glass 250 mL; Pipet Kapiler, Kertas Saring, Batang Pengaduk, Hot Plate, Oven, Plat Kromatografi Lapis Tipis, Chamber atau Bejana, dan Benang wol bebas lemak.

Bahan yang digunakan dalam penelitian ini adalah Sirup Bunga Rosella, Amoniak 10\%, Asam Asetat $10 \%$, Aqua destilata, Aseton pekat, Etil Metil Keton pekat, $\mathrm{NaCl} 2$ gram, Brilliant Blue FCF (Cl No. 42090) 20 ppm, Carmoisin (Cl No. 14720) 20 ppm, Dietil Eter pekat, $\mathrm{HCl} 0,1 \mathrm{~N}, \mathrm{NaOH} 10 \%, \mathrm{NaOH}$ 0,5\%, Etanol 50\%, Ponceau 4R (Cl No. 16255) 20 ppm, dan Rhodamin $B 0,01 \mathrm{~g}$ dalam $50 \mathrm{~mL}$ air.

\section{Prosedur}

Sampel dimasukkan ke dalam beaker glass 100 $\mathrm{mL}$ sebanyak $50 \mathrm{~mL}$. Asam asetat $10 \%$ ditambahkan ke dalam beaker glass sebanyak 5 $\mathrm{mL}$. Benang wol dimasukkan dan direndam ke dalam sampel tersebut kemudian dipanaskan dan didiamkan sampai mendidih (10 menit). Benang wol diambil dan dicuci dengan aquades. Amoniak 
$10 \%$ ditambahkan ke dalam benang wol yang sudah dibilas tersebut sebanyak $25 \mathrm{~mL}$. Benang wol dipanaskan sampai warna tertarik pada benang wol (luntur). Benang wol dibuang, larutan diuapkan sampai kering. Kemudian residu ditambahkan beberapa tetes metanol, untuk ditotolkan pada plat kromatografi yang siap pakai. Plat kromatografi ditotolkan sampel serta zat warna pembanding yang cocok. Jarak rambat elusi $12 \mathrm{~cm}$ dari tepi bawah plat. Plat Kromatografi dielusi dengan eluen I (Etil Metil Keton : Aseton : Air $=70: 30: 30)$ dan eluen II ( $2 \mathrm{~g} \mathrm{NaCl}$ dalam 100 $\mathrm{ml}$ etanol 50\%) kemudian plat kromatografi dikeringkan pada udara dan suhu kamar. Bercak yang timbul diamati secara visual dan dibawah cahaya lampu Ultraviolet (UV). Bercak mula-mula diamati dengan cahaya Ultraviolet gelombang pendek (254 nm) dan kemudian gelombang panjang $(366 \mathrm{~nm}$ ) jarak tiap bercak diukur dan dicatat (SNI, 1992).

\section{Analisis Data}

Analisis data dilakukan dengan menghitung nilai Rf sampel yang kemudian akan dibandingkan dengan nilai $R f$ baku pewarna sintetis yang digunakan yaitu Ponceau, Carmoisin, Briliant Blue dan Rhodamin B

\section{HASIL DAN PEMBAHASAN}

Berdasarkan hasil penelitian zat pewarna sintetis secara kualitatif menggunakan metode Kromatografi Lapis Tipis pada sampel dan baku pembanding diperoleh hasil pada tabel berikut:
Tabel 1. Hasil Pengujian Menggunakan Metode Kromatografi

\begin{tabular}{ccc}
\hline $\begin{array}{c}\text { Sampel } \\
\text { Pewarna }\end{array}$ & $\begin{array}{c}\text { Nilai Rf pada Eluen I } \\
\text { (Etil Metil Keton : } \\
\text { Aseton : Air) }\end{array}$ & $\begin{array}{c}\text { Nilai Rf pada Eluen } \\
\text { II }(2 \mathrm{~g} \mathrm{NaCl} \text { dalam } \\
100 \mathrm{ml} \text { Etanol } 50 \%)\end{array}$ \\
\hline Ponceau 4R & 0,7667 & 0,9400 \\
Carmoisin & 0,8266 & 0,9400 \\
Rhodamin B & 0,8667 & 0,6467 \\
Brilliant Blue & 0,7466 & 0,8867 \\
Sampel & - & - \\
\hline
\end{tabular}

Eluen I (Etil Metil Keton : Aseton : Air)

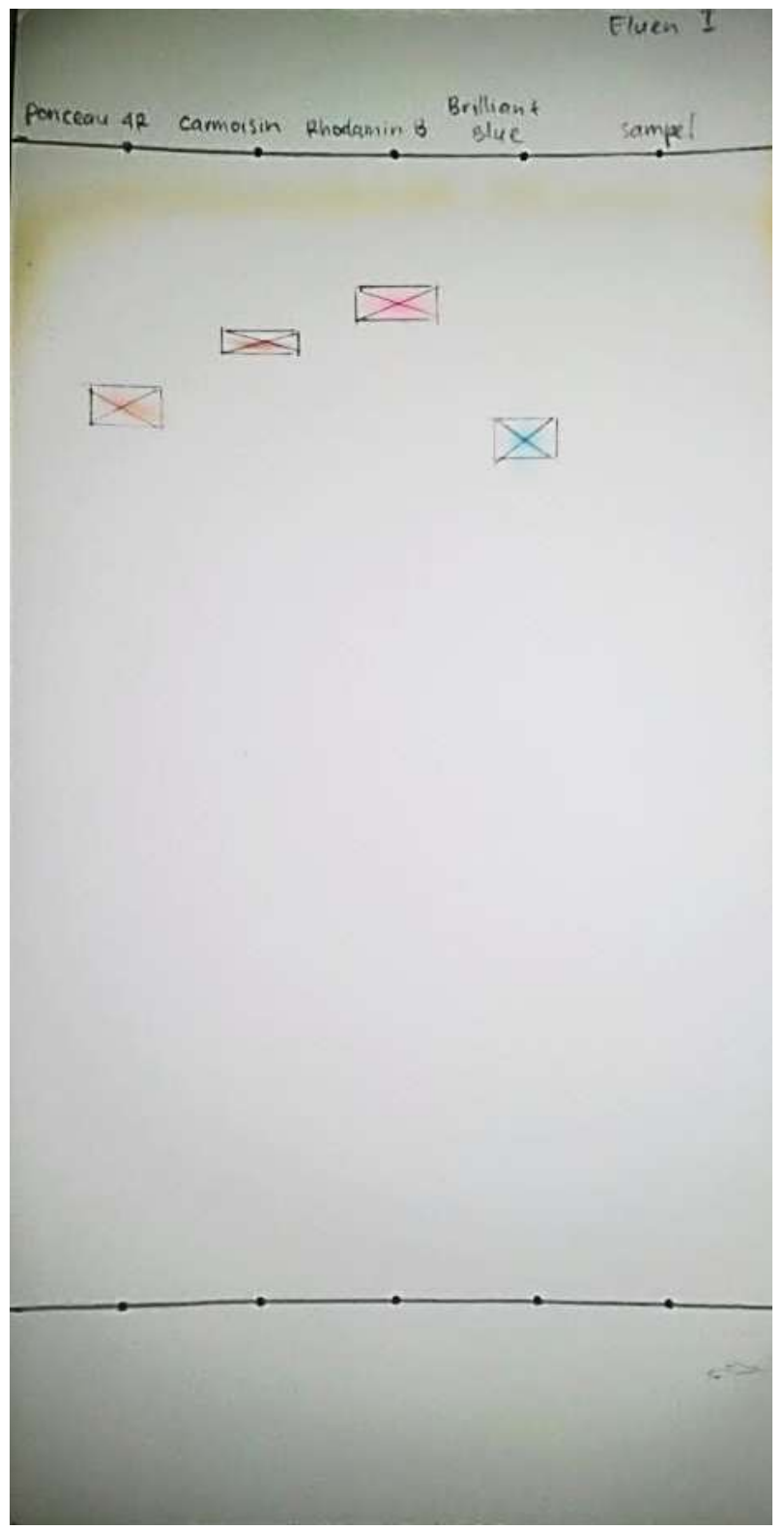




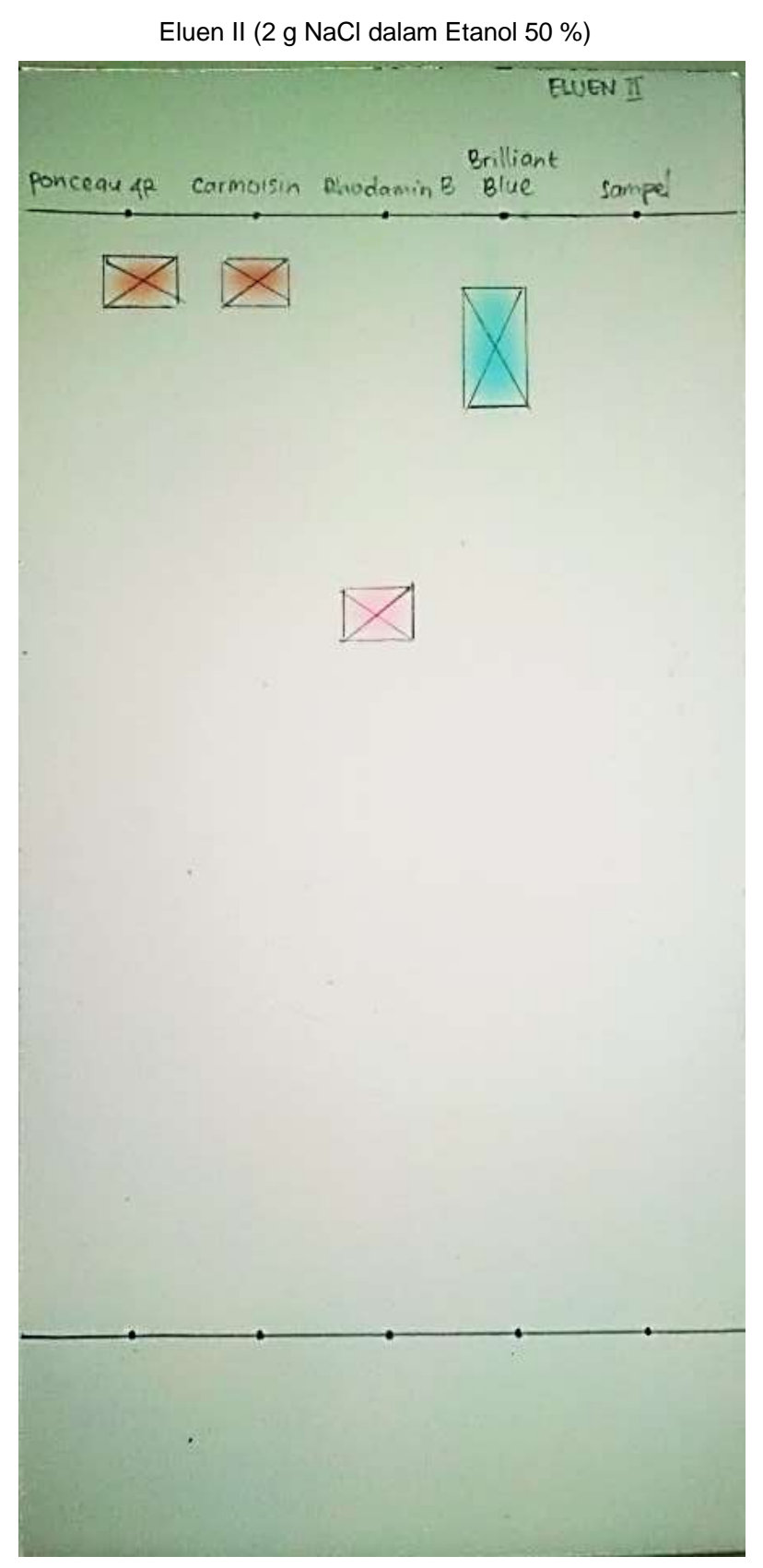

Gambar 1. Hasil Kromatogram

Sirup bunga Rosella dilakukan preparasi dan ekstraksi menggunakan benang wol bebas lemak yaitu dengan memasukan sebanyak $50 \mathrm{~mL}$ sampel sirup serta baku pembanding berupa zat pewarna sintetis yang diizinkan dan yang dilarang yaitu Ponceau 4R, Carmoisin, Brilliant Blue dan Rhodamin $B$ ke dalam masing-masing beaker glass $100 \mathrm{~mL}$ yang kemudian diasamkan dengan menambahkan $5 \mathrm{~mL}$ Asam Asetat 10\%. Memasukan dan merendam benang wol bebas lemak ke dalam masing-masing beaker glass tadi, kemudian dipanaskan dan didiamkan sampai mendidih. Dalam suasana asam dan pemanasan yang dilakukan, pewarna sintetis akan tertarik atau menempel pada benang wol bebas lemak. Pemanasan akan membantu mempercepat reaksi penarikan warna dengan benang wol bebas lemak, kemudian dicuci dengan aquades.

Masing-masing benang wol yang mengikat pewarna sintetis Ponceau 4R, Carmoisin, Brilliant Blue, dan Rhodamin B ditambahkan amoniak 10\% sebanyak $25 \mathrm{~mL}$ dan memanaskannya hingga warna pada benang menjadi luntur. Zat pewarna sintetis yang diizinkan pada makanan yaitu Ponceau 4R, Carmoisin dan Brilliant Blue setelah penambahan suatu basa lemah (Amoniak 10\%) dan pemanasan, warna pada benang wol menjadi luntur. Sedangkan zat pewarna sintetis untuk bahan tekstil yaitu Rhodamin $B$ setelah penambahan Amoniak $10 \%$ dan dilakukan pemanasan, warna pada benang wol tidak seluruhnya luntur. Penambahan $25 \mathrm{~mL}$ Amoniak $10 \%$ ke dalam benang wol bebas lemak dimaksudkan untuk melepaskan atau melunturkan pewarna yang ada pada benang wol tersebut sehingga larut dalam pelarut Amoniak. Dalam suasana basa lemah pewarna akan terlepas dari benang wol bebas lemak. Pelepasan warna pada benang wol bebas lemak dibantu dengan proses pemanasan yang menyebabkan warna akan lebih mudah terlepas dari benang wol, hal ini ditandai dengan jenuhnya pelarut Amoniak dari tidak berwarna menjadi berwarna. 
Pada Eluen I berupa Etil Metil Keton : Aseton : Air didapatkan nilai Rf masing-masing pewarna yaitu nilai Rf pada baku Ponceau $4 R$ sebesar 0,7667, nilai Rf baku Carmoisin sebesar 0,8266, nilai Rf baku Rhodamin $B$ sebesar 0,8667 , dan nilai $\mathrm{Rf}$ baku Brilliant Blue sebesar 0,7466. Sedangkan pada sampel sirup bunga Rosella tidak terdapat noda. Pada Eluen II berupa $2 \mathrm{~g} \mathrm{NaCl}$ dalam $100 \mathrm{~mL}$ Etanol 50\% didapatkan nilai $\mathrm{Rf}$ masing-masing pewarna yaitu nilai Rf pada baku Ponceau $4 R$ sebesar 0,9400, nilai Rf baku Carmoisin sebesar 0,9400, nilai Rf baku Rhodamin B sebesar 0,6467, dan nilai Rf baku Brilliant Blue sebesar 0,8867, sedangkan pada sampel sirup bunga Rosella tidak terdapat noda. Berdasarkan tabel diatas, sampel tidak mengandung pewarna sintetis Ponceau $4 R$, Carmoisin, Rhodamin $B$, dan Brilliant Blue, sedangkan pada sampel sirup bunga Rosella tidak terdapat noda sehingga Rf tidak ada. Hal ini dikarenakan pada proses preparasi warna pada sampel tidak tertarik oleh benang wol bebas lemak.

\section{KESIMPULAN}

Berdasarkan hasil identifikasi pewarna sintetis pada sirup produk olahan bunga Rosella dengan metode Kromatografi Lapis Tipis dapat disimpulkan bahwa sirup bunga Rosella asal Kelurahan Kalampangan, kota Palangka Raya tidak menggunakan pewarna sintetis baik yang diizinkan maupun yang dilarang.

\section{DAFTAR PUSTAKA}

Departemen Kesehatan Republik Indonesia. 1979. Farmakope Indonesia edisi III. Jakarta.

Departemen Kesehatan Republik Indonesia. 2012. Peraturan Menteri Kesehatan RI No. 033
Tahun 2012 tentang Bahan Tambahan Pangan. Jakarta

Departemen Perindustrian Republik Indonesia. 1992. SNI 01-2895-1992 Cara Uji Pewarna Tambahan Makanan. Jakarta

Irianto, Kus dan Kusno Waluyo. 2007. Gizi dan Pola Hidup Sehat. Bandung : CV. Yrama Widya. Dalam Purba, Elisabet R. 2009. "Analisis Zat Pewarna Pada Minuman Sirup Yang Dijual Di Sekolah Dasar Kelurahan Lubuk Pakam III Kecamatan Lubuk Pakam". Skripsi Fakultas Kesehatan Masyarakat Universitas Sumatera Utara.

Nugraheni, Mutiara. 2013. Pewarna Alami Sumber dan Aplikasinya pada Makanan \& Kesehatan. Yogyakarta, Graha IImu.

Purba, Elisabet R. 2009. "Analisis Zat Pewarna Pada Minuman Sirup Yang Dijual Di Sekolah Dasar Kelurahan Lubuk Pakam III Kecamatan Lubuk Pakam". Medan: Skripsi Fakultas Kesehatan Masyarakat Universitas Sumatera Utara.

Winarno, F.G. dan S.F. Rahayu. 1994. Bahan Tambahan untuk Makanan dan Kontaminan. Jakarta, Pustaka Sinar Harapan. 